\title{
ISOLATION, MOLECULAR CHARACTERISATION AND EXPRESSION LEVEL OF CYTOSOLIC HEAT-SHOCK PROTEIN 90 (HSP90) GENES OF CRYPTOCORYNE CILIATA, A HALOPHYTE PLANT
}

\author{
ZAIRUL FAZWAN ZAINORDIN, CHA THYE SAN AND AZIZ AHMAD*
}

Universiti Malaysia Terengganu, Kuala Terengganu, Malaysia.

*Corresponding author: aaziz@umt.edu.my

Submitted final draft: 26 January 2021 Accepted: 5 February 2021

http://doi.org/10.46754/jssm.2021.10.004

\begin{abstract}
Heat-shock protein 90 (HSP90) assembly in the cell involves protein-folding, as well as plant growth and response to environmental stimuli. Little is known regarding the sequence and function of HSP90s in halophytes plants. In the present study, a partial cDNA sequence of CcHsp90-1 and, a full-length cDNA of CcHsp90-2 from Cryptocoryne ciliata were cloned and sequenced. The full-length $C c H s p 90-2$ cDNA sequence, containing 2465 base pairs, encoding a protein of 700 amino acids. The molecular mass of CcHsp90-2 protein was estimated at $79.95 \mathrm{kDa}$, which is 89 to $94 \%$ homology to plant HSP90 protein. The protein possesses five-conserved amino acid signature sequence motifs characteristic of the HSP90 family and a C-terminus MEEVD penta-peptide characteristic, encoded by HSP90A group, which is mainly expressed in the cytosol. The predicted quaternary architecture structure for $\mathrm{CcHsp} 90-2$ protein generated through molecular modeling was globally akin to yeast HSP90. The CcHsp 90 s gene expression analyses in leaves of C. ciliata towards salinity treatment using the qRT-PCR analysis showed that both, CcHsp90-1 and CcHsp90-2 genes were significantly up-regulated with an optimum expression of 5.66 and 8.94-fold, respectively. It is suggested that few HSP90 isoforms might be synergistically exerted in regulating the salinity stress by $C$. ciliata.
\end{abstract}

Keywords: Chaperons, halophytes, nucleotide, penta-peptide, salinity.

\section{Introduction}

Mangrove plants that inhabit extreme conditions, i.e. brackish water with 10 to $50 \%$ more salinity than normal seawater (Simon et al., 2008; Ahmad-Sofiman et al., 2009) require a special osmotic adjustment for survival. The ability of this plant to grow under salinity stress is very interesting to explore. Salinity stress in plants is mainly caused by high $\mathrm{Na}^{+}$and $\mathrm{Cl}^{-}$ ion concentrations that leads to water-deficient cells (Roy et al., 2014), ionic stress, metabolic inhibition of cellular activities (Nakayama et al., 2005), changes in protein and/or enzyme functions, deleterious structure by impeding the balance of forces controlling the structure (Serrano et al., 1999), nutrient deficiencies and decreasing $\mathrm{CO}_{2}$ assimilation (Legay et al., 2009). High salt concentration decreases the water gradient, reducing the amount of nutrients that pass through the root membrane and cell expansion rates, and the plant eventually suffers shrinkage of leaf size, necrosis, which leads to the death of the leaf and the whole plant (Munns, 2002; Isayenkov \& Maathuis, 2019).

As sessile organisms, plants need osmotic adjustment and intercellular molecule changes for survival. Heat-shock proteins (HSPs)/ chaperones have been identified as the molecules involved in homeostasis and plays a crucial role in protecting plants against stresses. The HSPsproteins re-establish protein conformation through the folding, assembly, translocation degradation, stabilization of membrane protein (Wang et al., 2004; Wei et al., 2020). So far, more than twenty different family of HSPproteins that have chaperone activity have been discovered (Kosmaoglou et al., 2008). Five major HSPs/chaperones families have been classified according to their molecular weight, which are the small HSP family (12-40 KDa), HSP60 family (60 KDa), HSP70 family (70 KDa), HSP90 family (90 KDa), and HSP100 family (100 KDa) (Wang et al., 2004). HSP90 is one of the most abundant proteins expressed 
in cells under normal conditions that could be found in the cytosol, chloroplast, mitochondria and endoplasmic reticulum (Liu et al., 2006) of a eukaryote. In plants, HSP90 regulates and responds to heat, cold, salinity, heavy metals, phytohormones, and light/dark transitions (Wang et al., 2004) and drought (Wei et al., 2020) stresses. HSP90 also assists other proteins in achieving proper folding (Wang et al., 2004; Tichá et al., 2020), signal-transduction networks (Richter \& Buchner, 2001), cell-cycle control (Buchner, 1999), protein degradation and protein trafficking (Rutherford \& Lindquist, 1998; Krishna \& Gloor, 2001). Nevertheless, there are limited reports regarding the HSP90 in aquatic plants under salinity stress and most of the studies focus on glycophytes e.g. rice, maize, soybean, potato, and beans (Mahajan \& Tuteja, 2005; Li et al., 2020).

Liu et al. (2006) reported that overexpression of HSP90 s improved the heat-shock and salt-stress tolerance in tobacco and yeast. However, many mechanism issues, such as the machinery of HSP/chaperones, communication of specific HSP/chaperones in a crowded cellular environment, the specific regulation of HSP/ chaperones molecules, participation in stress sensing, signal transduction and transcription activation of stress genes remain unknown. Thus, the characterization of the HSP90 gene in salinity-tolerant aquatic plants could permit a greater understanding of the molecular mechanisms in plants facing salinity stress. This study aim to conduct a systematic search for the HSP90 gene expression levels in Cryptocoryne ciliata, a halophyte plant under salinity stress using quantitative polymerase chain reaction (qRT-PCR) t.

\section{Materials and Methods}

\section{Plant Material and cDNA Synthesis}

Established in vitro cultures of $C$. ciliata that were maintained in B5 basal medium (Gamborg, 1967) were used as sources of genetic material. The plantlets were immersed in filtered seawater $(29.0 \mathrm{ppt})$ for 24 hours to induce the expression of salt tolerance genes. The total RNA was isolated using a GF-1 Total RNA Purification Kit (Vivantis, Malaysia) according to the manufacturer's instructions. The cDNA was synthesized using the M-MuLV Reverse Transcriptase enzyme (Fermentas, Lithuania). One $\mu \mathrm{g}$ of total RNA was mixed with 0.5 $\mu \mathrm{g}$ oligo- $(\mathrm{dT})_{18}$ primer (5'-d (TTT TTT TTT TTT TTT TTT)-3') (Fermentas, Lithuania). Subsequently, DEPC-treated water was topped to $10 \mu \mathrm{l}$ before incubated at $70^{\circ} \mathrm{C}$ for $5 \mathrm{~min}$ and chilled on ice for $1 \mathrm{~min}$. The mixture was briefly centrifuged and $4 \mu 1$ of 5 X RT buffer, $2 \mu 1$ of 10 mM dNTP mix, and $2 \mu \mathrm{l}$ of M-MuLV reverse transcriptase enzymes were added. The mixture was incubated at $37^{\circ} \mathrm{C}$ for 1 hour followed by a terminating stage at $70^{\circ} \mathrm{C}$ for 10 minutes before being centrifuged briefly and kept on ice.

\section{Multiplex-Polymerase Chain Reaction (Multiplex-PCR)}

Multiplex-PCR was performed in $25 \mu$ reaction mixture consisting of $2.5 \mu \mathrm{l}$ of $10 \mathrm{X}$ PCR Buffer, $8.0 \mathrm{mM} \mathrm{MgCl}{ }_{2}, 0.2 \mathrm{mM}$ dNTP, $1.0 \mathrm{U}$ Taq polymerase (Fermentas, Lithuania), 1.0 $\mu \mathrm{M}$ of each three reverse and three forward degenerate primers designed using FastPCR Professional version 5.4.12 software (Table 1), 200ng cDNA and $\mathrm{ddH}_{2} \mathrm{O}$ using Mastercycler Gradient (Eppendorf, Germany). The general program of multiplex-PCR was started with an initial denaturation at $94^{\circ} \mathrm{C}(3 \mathrm{~min})$ followed by 35 cycles: $94^{\circ} \mathrm{C}(30 \mathrm{sec}), 50^{\circ} \mathrm{C}(1 \mathrm{~min})$, and $72^{\circ} \mathrm{C}(90 \mathrm{sec})$, before final extension periods of incubation at $72^{\circ} \mathrm{C}(10 \mathrm{~min})$. The PCR products were electrophoresed in $1.5 \%(\mathrm{w} / \mathrm{v})$ agarose gel mixed with $1 \mathrm{x}$ TAE buffer $\mathrm{pH} 8.0$ and 10 $\mu \mathrm{g}$ of ethidium bromide at 80 volts for $45 \mathrm{~min}$. Bands produced were analysed using an Image Master Video Documentation System (VDS). The expected fragments of Multiplex-PCR ( $\sim 300$ to $700 \mathrm{bp}$ ) were purified using a Wizard $\AA$ SV Gel and PCR Clean-Up System (Promega, USA). The purified bands then were cloned into pGEM-T Easy Vector (Promega, USA) and transformed into the $E$. coli strain DH5 $\alpha$ host cells using heat shock method (Froger \& 
Table 1: The list of degenerate primers used in Multiplex-PCR for $C c H s p 90$ gene isolation

\begin{tabular}{llccc}
\hline \multicolumn{1}{c}{ Primers } & \multicolumn{1}{c}{ Sequence $\left(\mathbf{5}^{\prime} \rightarrow \mathbf{3}^{\prime}\right)$} & $\begin{array}{c}\text { Nucleotide } \\
\text { Position }\end{array}$ & $\begin{array}{c}\text { Length } \\
\text { (base) }\end{array}$ & $\begin{array}{c}\mathbf{G}+\mathbf{C} \\
\mathbf{( \% )}\end{array}$ \\
\hline Hsp90aF & GTSTTYATYATGGAYAACTG & $1087 \rightarrow 1107$ & 20 & 37.5 \\
Hsp90bF & CARCAGAATAAGATYCTNAAGGT & $1194 \rightarrow 1217$ & 23 & 37.0 \\
Hsp90cF & AAGAARTGYVTYGAGMTNTTC & $1237 \rightarrow 1258$ & 21 & 38.9 \\
Hsp90aR & GGNGARTTCTCMACVGCCTT & $1483 \rightarrow 1503$ & 20 & 55.8 \\
Hsp90bR & CTCHARGAABGGNGARTTCTC & $1492 \rightarrow 1513$ & 21 & 50.0 \\
Hsp90cR & TCNCCDGTNCANARRCAGACA & $1774 \rightarrow 1795$ & 21 & 51.6 \\
\hline
\end{tabular}

Hall, 2007). Plasmids extracted from positive recombinant colonies were sequenced (Axil Scientific Pte. Ltd.) and analysed using the Basic Local Alignment Search Tool (BLAST) for the confirmation.

\section{Full-length of the Specific cDNA Fragment}

The 3'- and 5'-RACE was carried out to obtain the full-length of cDNA gene sequence. A new forward primer for the 3'-RACE technique was designed based on the partial fragment of putative CcHsp90 gene from multiplex-PCR sequencing result using the FastPCR Professional version 5.4.12 software. The first-strand cDNA synthesis was carried out with $1.0 \mu \mathrm{l}$ of $10 \mu \mathrm{M}$ KPN-T17 (5'-TCA GTG ACG AGG TAC CGA GCT CAA GCT TTT TTT TTT TTT TTT T-3') primer using thermal cycler in thin-walled PCR amplification in $50 \mu \mathrm{l}$ reaction mixture. The mixture consists of $5 \mu \mathrm{l} 10 \mathrm{X}$ PCR Buffer, 1.5 $\mathrm{mM} \mathrm{MgCl}{ }_{2}, 0.2 \mathrm{mM}$ dNTP, $1.0 \mathrm{U}$ Taq Polymerase (Fermentas, Lithuania), $1.0 \mu \mathrm{M}$ specific forward primers (5'-AAC CAG CCT CAA GGA CTA CGT-3'), $1 \mu$ of KPN adaptor (5'-AGT GAC GAG GTA CCG AGC TCA AGC-3') primer, 200 ng cDNA template and $\mathrm{ddH}_{2} \mathrm{O}$. The PCR program Mastercycler Gradient, (Eppendorf, Germany) was initial denaturation at $94^{\circ} \mathrm{C}$ for 3 min; 40 cycles at $92^{\circ} \mathrm{C}$ for $30 \mathrm{sec}$ (denaturation), $60^{\circ} \mathrm{C}$ for $90 \mathrm{sec}$ (annealing) and $72^{\circ} \mathrm{C}$ for $2 \mathrm{~min}$ (extension); final extension at $72^{\circ} \mathrm{C}$ for $10 \mathrm{~min}$. The expected fragments of 3'-RACE ( 1000 bp) then were purified using a Wizard ${ }^{\circ}$ SV Gel and PCR Clean-Up System (Promega, USA), and subsequently cloned into pGEM-T Easy Vector (Promega, USA) and transformed into the $E$. coli strain DH5 $\alpha$ host cells using the heat shock method (Froger \& Hall, 2007). Plasmid DNA of positive recombinant colonies were sequenced (Axil Scientific Pte. Ltd.) and confirmed using BLAST by BLAST. Meanwhile, the 5'-RACE analysis was performed using the 5'-RACE System for Rapid Amplification of cDNA Ends, Version 2.0 kit (Invitrogen, USA). The Gene-Specific reverse Primers (GSP1) for firststrand cDNA synthesis; GSP2 and GSP3 for PCR primer in Table. 2 were designed using the FastPCR Professional version 5.4.12 based on 3'-RACE results. The 5'-RACE procedures were repeated until full-length sequences were obtained. The 3'- and 5'-RACE products were electrophoresed $(1.5 \%$ agarose gel added with 1x TAE buffer $\mathrm{pH} 8.0$ and $10 \mu \mathrm{g}$ of ethidium bromide, at 80 volts for $45 \mathrm{~min}$ ) and the expected size of the PCR products $(\sim 1000 \mathrm{bp})$ were purified using the Wizard ${ }^{\circledR}$ SV Gel and PCR Clean-Up System (Promega, USA), cloned into pGEM-T Easy Vector (Promega, USA), transformed into the E. coli strain DH5 $\alpha$ host cells and confirmed as above.

\section{CcHsp90-2 Sequence Analysis}

Two isoforms of HSP90 genes were successfully isolated, namely the CcHsp 90-1 and CcHsp 90-2. However, only the full-length of CcHsp90-2 cDNA was characterized, while the CcHsp90-1 cDNA sequence remained partial. The open reading frame (ORF) region of $\mathrm{CcHsp}$ 90-2 genes 
was identified and translated using the ExPASy protein translation tools (http://web.expasy.org/ translate/) before proceeding with other analyses. The CcHsp90-2 protein's molecular weight was predicted using an online software (http:// www.sciencegateway.org/tools/proteinmw. htm). All the HSP90 conserved domains in CcHsp90-2 predicted amino acid sequences that were determined using the multiple alignment ClustalW2 (http://www.ebi.ac.uk/Tools/msa/ clustalw2/) and compared with Pennisetum glaucum cytosolic HSP90 characterized by Reddy et al. (2011). The HSP90 important residues were experimentally identified based on Chen, et al. (2006) using the ClustalW2 software. The predicted quaternary architecture structure for CcHsp90-2 protein was analysed using the homology modelling server SWISS-MODEL (Arnold et al., 2006 and Kiefer et al., 2009) based on yeast HSP90 protein crystal structure [2cg9B]. The CcHsp90-2 proteins subfamily determined by HSP90 proteins signature sequences was described as suggested by Chen et al. (2006). Phylogenetic analysis of CcHsp90 proteins were performed using seven different HSP90 isoforms from the Arabidopsis genome (GenBank: NP 200076.1, NP_200414.1, NP_200412.1, NP_200411.1, NP_178487.1, NP_187434.2 and NP_194150.1), seven different HSP90 isoforms from rice genome (GenBank:NP_001063504.1,NP_001063503.1, NP_001063500.1, NP_001062159.1, NP $001063456.1, \quad$ NP 001066882.1 and NP_001058590.1), cytosolic HSP90 of Dactylis glomerata (ACX37413.1), Hordeum vulgare (AAP87284.1) and Pennisetum glaucum (ADP89125.1) that consists of cytosolic, mitochondrial, chloroplast and endoplasmic reticulum HSP90 using the ClustalW2 analysis.

\section{CcHsp90-1 and CcHsp90-2 Transcription Levels}

A two-month-old in vitro plantlets of $C$. ciliata that were maintained in B5 medium (Gamborg, 1967) were immersed in filtered seawater $(29.0$ ppt) for $0,4,8,12$ and $24 \mathrm{~h}$. Subsequently, the total RNA was isolated from the mature leaves using the GF-1 Total RNA Extraction Kit (Vivantis, Malaysia) according to the manufacturer's instructions. The quantitative real-time PCR (qRT-PCR) was performed in MyiQ2 Two-Colour Real-Time PCR Detection System (Bio-Rad) using the iQSYBR Green Supermix (Bio-Rad) according to the manufacturer's instructions. Total RNA (1.0 $\mu \mathrm{g})$ was reverse transcribed for standardization using $0.2 \mu \mathrm{g}$ of random hexamers primer (Fermentas, Lithuania) with $0.5 \mu \mathrm{g}$ oligo-(dT) ${ }^{18}$ primer (Fermentas, Lithuania) and used as a template for $\mathrm{qPCR}$ analysis. The $25 \mu \mathrm{l}$ reaction mixture consisted of $50 \mathrm{ng}$ of cDNA, $0.3 \mu \mathrm{M}$ final concentration of each forward and reverse specific primers (Table 2), $10 \mu \mathrm{L} 2 \mathrm{X}$ iQSYBR Green Supermix, and nuclease-free water to the final volume. After heating at $95^{\circ} \mathrm{C}$ for $3 \mathrm{~min}$, the real-time PCR amplification was programmed for 40 cycles of $94^{\circ} \mathrm{C}$ for $35 \mathrm{~s}$, $57.5^{\circ} \mathrm{C}$ for $35 \mathrm{~s}$, and $72^{\circ} \mathrm{C}$ for $30 \mathrm{~s}$. The specific primer for the CcHsp90-1 and CcHsp90-2 genes were designed based on the dissimilarity region to genes sequence to avoid missed amplification or overlaps in the target gene. The specificity of all PCR amplifications was verified by a melting curve after each run, which was set from $55^{\circ} \mathrm{C}$ to $95^{\circ} \mathrm{C}$ in $0.5^{\circ} \mathrm{C}$ increments. The gene expression was quantified using the $2^{-\Delta \Delta \mathrm{Ct}}$ method (Livak \& Schmittgen, 2001). Results were analysed using the iQ5 Standard Edition version 2.0.148.60623 (Bio-Rad), Relative Expression Software Tool (REST) version 2.0.13 (Pfaffl et al., 2002), and Microsoft Excel. The excitation and emission were at $492 \mathrm{~nm}$ and $526 \mathrm{~nm}$, respectively. Standard curves generated for the specific primer of CcHsp90-1, CcHsp90-2, and Cc18S $r R N A$ were set approximately at -3.32 with the correlation coefficient higher than 0.99 . The slope of calibration curves was at $-1 / \log 10(2)$ $=-3.32$ (Liss, 2002), where the efficiency was equalled to 2 or $100 \%$ and the differences in the primer efficiency between the target primer and reference primer pairs were below $5 \%$. 
Table 2: List of primers used in CcHsp90-2 gene isolation and expression analysis

\begin{tabular}{|c|c|c|c|c|}
\hline Primer & Primer Sequence $\left(5^{\prime} \rightarrow 3^{\prime}\right)$ & $\begin{array}{c}\text { Length } \\
\text { (base) }\end{array}$ & $\operatorname{Tm}\left({ }^{\circ} \mathbf{C}\right)$ & $\mathbf{G}+\mathbf{C}(\%)$ \\
\hline \multicolumn{5}{|c|}{ 5'-RACE primers in $\mathrm{CcHsp90-2}$ gene isolation } \\
\hline \multicolumn{5}{|l|}{ pCcHsp90-2.2 } \\
\hline Hsp90-2a (GSP1) & GGGTTTCCTTCTTTT & 15 & 44.7 & 40 \\
\hline Hsp90-2A (GSP2) & TTCTCGTCCTCACTCTCATCA & 21 & 60.0 & 47.6 \\
\hline Hsp90-2B (GSP3) & AGCTTGAGCCCCTCCTTAGTG & 21 & 63.1 & 57.1 \\
\hline \multicolumn{5}{|l|}{ рCcHsp90-2.3 } \\
\hline Hsp90-U (GSP1) & TTTTGTTGAAGCATCTCA & 18 & 51.7 & 33.3 \\
\hline Hsp90-2C (GSP2) & CGGGAAATGTTTAGCGGCAAA & 21 & 60.8 & 47.6 \\
\hline Hsp90-2D (GSP3) & CACAAAGCTCAGATATTCTGG & 21 & 57.5 & 42.9 \\
\hline \multicolumn{5}{|l|}{ pCcHsp90-2.4 } \\
\hline Hsp90-2b (GSP1) & CTTAGAAGTGACGATAA & 17 & 48.2 & 35.3 \\
\hline Hsp90-2E (GSP2) & CAAGGTAGGCGGAGTAAAATC & 21 & 58.0 & 47.6 \\
\hline Hsp90-2F (GSP3) & СTGACCTATCATGCTTACATC & 21 & 56.2 & 42.9 \\
\hline \multicolumn{5}{|c|}{ qRT-PCR primers in gene expression } \\
\hline RT-Cc18S rRNA F & TCGGTCCTATTGCGGTTGGCC & 21 & 63.8 & 61.9 \\
\hline RT-Cc18S rRNA R & GTATCTGATCGTCTTCGAGCC & 21 & 60.4 & 52.4 \\
\hline RT-CcHsp90-1 F & AGGAACTCATCCCCGAGTATT & 21 & 58.6 & 47.6 \\
\hline RT-CcHsp90-1 R & AАGCTCTATACATTTCTTGACA & 22 & 55.7 & 31.8 \\
\hline RT-CcHsp90-2 F & GAGGAGCTCATTCCAGAATATC & 22 & 58.4 & 45.5 \\
\hline RT-CcHsp90-2 R & AGTTCCACACACTTCTTAACC & 21 & 55.5 & 42.9 \\
\hline
\end{tabular}

\section{Results and Discussion}

\section{Isolation of Full-length CcHsp90-2 Gene}

Results showed that the 3'-RACE was the expected amplification product (987 bp) positively hits to HSP90 genes from other plants ( 89 to $92 \%$ homology). The isolated fragment (pCcHsp90-2.1) consisting of $711 \mathrm{~N}$ of partial ORF region with TAA stop codon, $250 \mathrm{~N}$ of 3'-untranslated region (3'-UTR), and $25 \mathrm{~N}$ of the polyA-tail region were successfully cloned and sequenced. However, the 5'-RACE produced three fragments [(pCcHsp90-2.3, 806 bp), (pCcHsp90-2.3, 907 bp) and (pCcHsp90-2.4, $481 \mathrm{bp}$ )] showing 91 to $97 \%$ homology to other plant HSP90 genes, consisting of $1588 \mathrm{~N}$ of the partial ORF region, $72 \mathrm{~N}$ of 5 '-untranslated region (5'UTR) and $16 \mathrm{~N}$ of cap region. Fulllength CcHsp90-2 nucleotide sequence (2465 bp) was successfully isolated and registered
(GenBank: JN210012). The overview activities of CcHsp90-2 gene, 3'-RACE and 5'-RACE fragments, and overlapping regions are shown in Figure 1. The isolation of the above genes involved three major steps: the initial gene isolation using a combination of degenerate primers and multiplex-PCR, 3'-RACE and 5'-RACE. Degenerate primer is a mixture of similar primers but different bases at the variable positions (Löffert et al., 1998). This approach is widely used in gene isolation (Duwat et al., 1992; Borrone et al., 2004; Heffer \& Pick, 2011). The specific degenerate primers for cytosolic HSP90 of $C$. ciliata were designed based on conserved regions of different genes encoding for cytosolic HSP90 isoforms from GeneBank. Meanwhile, the Multiplex-PCR technique allows the rapid detection of deletions or duplications in a large gene and amplifies more than one target sequence by adding multiple primer-pairs in a one reaction 
mixture (Elnifro et al., 2000). Furthermore, the successes of the technique were reported in gene deletion analysis (Aziza et al., 2002), mutation and polymorphism analysis (Prasad et al., 2000; Hayden et al., 2008), quantitative analysis (Sherlock et al., 1998) and RNA detection (Zou et al., 1998). Thus, a combination of degenerate primers and multiplex-PCR approach are the correct tools for the initial isolation of $\mathrm{CcHsp} 90$ genes. Combinations of 3'-RACE and 5'RACE sequencing produced a complete gene sequence of CcHsp90-2. In the early stage, 5'-RACE amplified only partial sequences of CcHsp 90-2 genes. A new set of specific reverse primers redesigned based on the previous 5'RACE fragment sequence had shown the way to obtain the full length of the gene sequence. The primers were designed at $\sim 250$ to $300 \mathrm{bp}$ from 5'-end of previous 5'-RACE product for creating the "overlapping region" to avoid miss joining of the fragments (Matesic et al., 2001; Kim et al., 2008), which resulted in the full-length CcHsp90-2 gene (pCcHsp90-2.2,

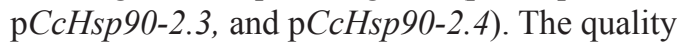
and secondary structure of the RNA sample are two critical factors that may influence the success of the 5'-RACE procedure (Invitrogen, 2004). Low RNA quality could result in partial sequences. Meanwhile, at low temperatures, the hydrogen bonds formed within the complementary pairs C-G and A-U RNA bases are stronger and form a loop structure. These secondary structures will synthesize the partial sequence and miss-pairing bases during the reverse-transcript process (Condon, 2003).

\section{Characterization of CcHsp90-2 cDNA}

Results of the present study showed that the fulllength CcHsp90-2 cDNA (2465 N) consists of a $16 \mathrm{~N}$ cap region, $72 \mathrm{~N}$ 5'-UTR region, 2100 $\mathrm{N}$ ORF region (stop codon TAA, expected to encode 700 amino acids), $250 \mathrm{~N}$ 3'-UTR region and $25 \mathrm{~N}$ poly-A tail (Figure 1 and 2). The cap region is important for recognition and proper attachment of mRNA to the ribosome, as well as protection from 5' exonucleases (O'mullane \& Eperon, 1998). Even though the cap region,
5'-UTR, 3'-UTR, and poly-A tail region do not encode any protein, they play key roles in protein translation that control gene expression (Ryan \& Bauer, 2008; Neilson \& Sandberg, 2010). Poly-A tail plays an important role in nuclear export, translation and CcHsp90 mRNA stability (Ito-Harashima et al., 2007; Chatterjee \& Pal, 2009). Normally, the size of the poly-A tail is reduced over time and the mRNA enzymatically degrades when it is short (Barsanjit et al., 2003). Nevertheless, in a few cells, mRNAs with short poly-A tails are stored for later activation by re-polyadenylation in the cytosol of oocytes (Richter, 1999).

The estimated molecular mass of the CcHsp90-2 predicted protein $(79.95 \mathrm{kDa})$ is almost similar to other plant HSP90 proteins, which are $A$. thaliana, 80.06 to $80.15 \mathrm{kDa}$ (Krishna and Gloor, 2001), P. glaucum, 80.28 $\mathrm{kDa}$ (Reddy et al., 2011) and H. vulgare, 80.43 $\mathrm{kDa}$ (Takahashi et al., 2003). It consists of four domains; N-terminus ATP binding domain (1211), charged-linker domain (211-280), middleclient protein interacting domain (281-540), and C-terminus dimerization domain (542-700) (Figure 3).

The predicted CcHsp90 N-terminus domain is responsible for the weak intrinsic ATPase activity of HSP90 due to the ATP inhibitor binding site (Prodromou et al., 1997; Stebbins et al., 1997; Wandinger et al., 2008). This finding is strongly supported by identification of important residues, which are ATP hydrolysis (E35), ATP binding (D81), geldanamycin and p23 binding (G83, G120, G123, G125 and G172), phosphorylation by casein kinase II (S220) and glutamic acid-rich region that slightly differ from human HSP90AA (Chen et al., 2006) as shown in Figure 3. In a suitable protein substrate, HSP90 will utilise the ATP and release the adenosine diphosphate (ADP) and phosphate $\left(\mathrm{P}_{\mathrm{i}}\right)$. However, inhibition of ATPase activity using direct inhibitor or allosterics, such as geldanamycin antibiotic, where the binding site is located at the predicted CcHsp90 N-terminus can block HSP90 function (Wandinger et al., 2008). In the meantime, the co-chaperone p23 
protein modulates HSP90 activity during the last stages of the chaperoning pathway, functioning as a substrate release factor by coupling the ATPase activity of HSP90 to polypeptide dissociation (Young \& Hartl, 2000; Felts \& Toft, 2003). The HSP90 protein can adopt two major conformational states, the open ATP-bound state and the closed ADP-bound state. Therefore, ATP hydrolysis drives are commonly referred to as a pincer-type conformational change in the protein binding site (Grenert et al., 1997)

The middle domain of CcHsp90-2 protein region that contains the ATPase activity (R372 and Q376) and interdomain interaction (F341) functional residues is considered a major site for client protein interactions, such as with protein kinases and hormone receptors (Wegele et al., 2004). CcHsp $90 \mathrm{~N}$-terminal domain is connected to the middle domain through a highly charged linker region. Meanwhile, the linker region plays important roles in the HSP90 mechanism. Hainzl et al. (2009) demonstrated that deletion of the charged linker ultimately causes a loss of HSP90 regulation. CcHsp90 C-terminus domain that is important for dimerization was identified with the presence of tetratricopeptide repeat (TPR) motif recognition site MEEVD penta-peptide. It's responsible for the interaction with co-chaperones, such as the immunophilins FKBP51 and FKBP52, the stress-induced phosphoprotein 1 (Sti1/Hop), cyclophilin-40, PP5, Tom 70 and other proteins to form a HSP90complex protein (Young et al., 1998) that are also important for dimerization (Freeman et al., 1995; Reddy et al., 2011) of CcHsp90-2 genes that encode functional proteins.

The predicted structure of CcHsp90-2 protein was generated using Swiss-Model Automatic Modelling software by utilizing yeast HSP90 protein crystal structure as a template with $62.16 \%$ identity (Table 3 ). With limited information, a predicted molecular model of CcHsp90-2 was constructed based on the available structural information from a closely related heterologous source (yeast) as an alternative (Figure 4). The structural information of predicted CcHsp90-2 protein facilitates its mode of action. Even though the structures of HSP90 are slightly different from other species, the biochemical functions are similar due to their amino acid sequence identities that are highly conserved (Chen et al., 2006).

HSP90 protein lacks nuclear localization sequences. Therefore, specific HSP90 families (cytosolic, chloroplast, mitochondrial and endoplasmic reticulum) can be transported to other parts of the cell by co-transport with client proteins (Taipale et al., 2010). Analysis of predicted CcHsp90-2 protein shows it contains all the signature sequences of the HSP90A subfamily (cytosolic) group the (Figure 2); [SLIINT (19-24), NNLGTIA (93-99), SMIGQFGVGFYS (118-129), AGG (154-156), RGT (171-173), KHFSVEGQLEF (299-309), VKK (389-391), HED (422-424), TGE (467469), IDEY (497-500), QALRD (589-593)] with $\mathrm{C}$-terminus cytosolic isoform-specific signature motif MEEVD at the end of the sequence (Figure 2). The results were supported by the phylogenetic analysis of predicted CcHsp90-2 sequences in Figure 4, showing that it has four monophyletic clades; chloroplast, mitochondria, endoplasmic reticulum, and cytosol specific isoforms. The predicted CcHsp90-2 proteinsequence was significantly homologous to plant cytosolic HSP90 at 94\% identity, but distinctly different from chloroplast, mitochondria and endoplasmic reticulum HSP90 families. Every HSP90 family has their own signature: cytosolicspecific HSP90 isoforms signature located at C-terminus (MEEVD motif), endoplasmic reticulum-specific HSP90 isoforms signature located at C-terminus (HDEL motif) and characteristic chloroplast and mitochondrion-

Table 3: Model information of CcHsp90-2 predicted protein

\begin{tabular}{lcccc}
\hline Protein Name & $\begin{array}{c}\text { Modelled Residue } \\
\text { Range }\end{array}$ & Template & $\begin{array}{c}\text { Sequence Identity } \\
\text { (\%) }\end{array}$ & E-value \\
\hline $\mathrm{CcHsp} 90-2$ & 5 to 669 & $2 \operatorname{cg} 9 \mathrm{~B}(3.10 \AA)$ & 62.16 & $0.00 \mathrm{e}-1$ \\
\hline
\end{tabular}


specific HSP90 located at N-terminus extension of the signal peptide sequence (Reddy et al., 2011). The branching pattern of the phylogeny tree showed that the chloroplast, mitochondria, endoplasmic reticulum and cytosol specific paralogous HSP90 families had diverged from each other at an early stage of evolution (Reddy et al., 2011). Although the cellular localization patterns are distinct, it is believed that the biochemical functions of these HSP90 proteins are predicted to be similar as their amino acid sequence identities to other eukaryotic HSP90s are significantly higher (Chen et al., 2006).

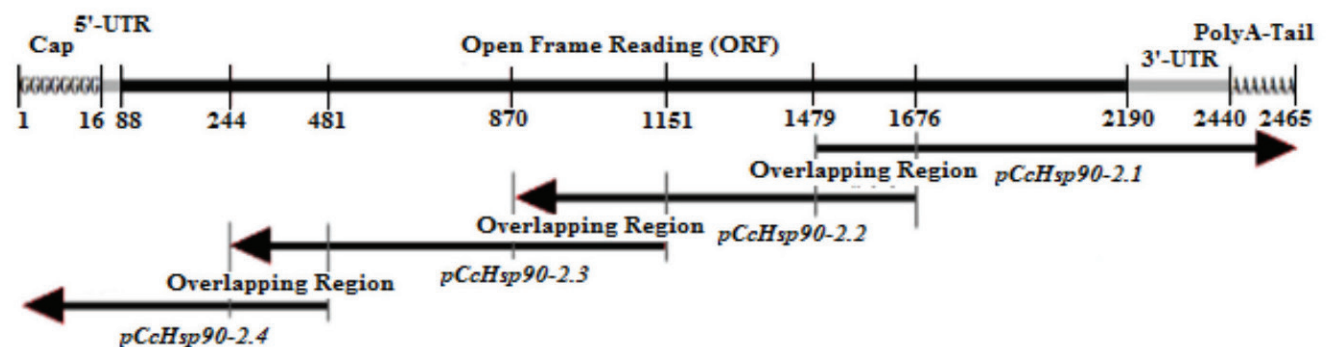

Figure 1: Overview of full-length $\mathrm{CcHsp90-2}$ gene isolation map that consist of four fragments with total length 2465 bp using 3'- and 5'-RACE approaches

5'GGGGGGGGGGGGGGGGAACCCTAACGGGCGCCGTTTCTGTGGTTGTGCGTCGGTTTCGGCTTCGTCTCGCAGGCCGCAGGGCGGAGG 8Q atggcagcggagacggagaccttcgccttccaggcggagatcaaccagcttctcagtctcatcatcaacaccttctactccaacaaggaaatcttccttcgggaactcatcagcaactcgtccgat 214

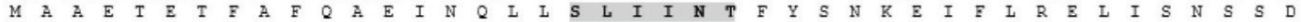
gcactcgataagatccgtttcgagagcctgacagataagagcaagctcgatgcgcagcccgagctcttcatacacatcgtccctgacaaggctaacaatagcctctccaccatcgatagtggcatt 340

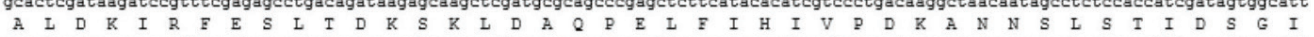
ggcatgaccaagtccgatttggttaacaatctgggcaccattgcaagatcggggaccaaggagttcatggaggcgttagctgcgggtgcggatgtaagcatgataggtcagtttggegttggattt 466

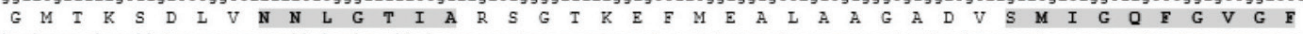
tactccgcctaccttgtcgecgagaaggttatcgtcacttctaagcacaatgacgacgaacaatacatatgggagtcceaggcaggtggttcattcacagtcaccagggatacctccggtgagaac 592

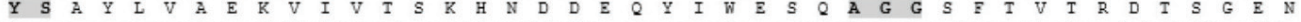
ctcggaagaggaacgaagatgacccttttettaaggatgaccagttagaatatcttgaggagcgccggctgaaggatctggtaaagaaacattccgagttcattagctatcctatttcgctttgg 718

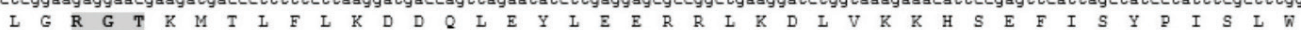
actgagaagacaacggaaaaggaatttctgacgatgaagatgatgatgacaagaaggatgaggagggtaaggtagaggatcttgacgaagaaaggaagaagagaaaaagaagaeaeagaaaatc 844

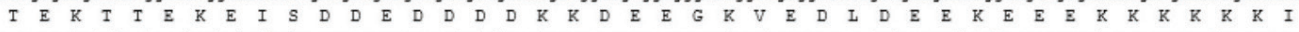
aaggaggtatctcatgagtggtctcttgtcaacaagcagaagectatctggatgaggaagccggaggagatcactaaagaggagtatgcagctttctacaagagcctgacaaacgactgggaagaa 970

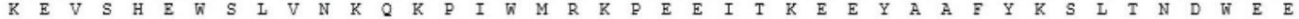
cattagctgtcaagcacttctctgtggaaggccaacttgaattcaaggccatcttgttcgtacccaagagggcaccttttgacctcttgacacaaggaagaagctgaacaacattaagctttat 1096

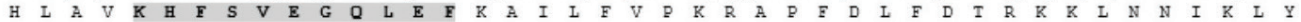
gttaggcgtgtttttatcatggacaactgcgaggagctcattccagaatatctgagctttgtgaagggtattgtggattcggaggatttgccgctaaacatttcccgtgagacgcttcaacaaaat 1222

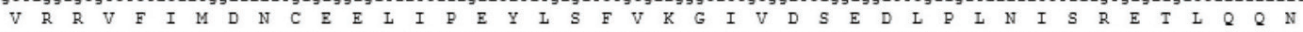
aagatcctcaaggttattcgcaagaatctggttaagaagtgtgtggaactcttcttgaaattgctgaaaacaggaagattacaacaagttctacgaggctttctccaagaatcttaaactcgge 1348

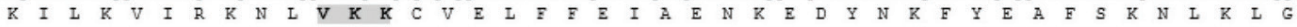
atccacgaggatactcagaatagatctaagctcgccgagt tgctcagatttaattctacgaagagtggagatgagttgacgagtctcaaggattacgtgactagaatgaaagaaggtcagagtgac 1474

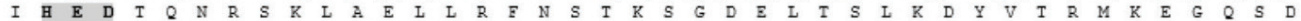
atctactacatcacgggtgagagcaagaaagcagttgagaattccccactcctcgagaagctgaagaagaagggttacgaggtectcttcatggttgatgccattgacgagtatgctgtggggcaa 1600

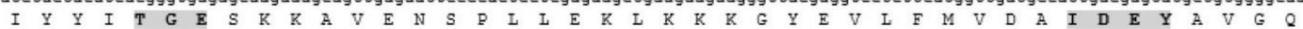
ctcaaggacttcgaaggcaagaagctcgtttctgccactaaggaggggctcaagcttgatgagagtgaggacgagaagaaaagaaggaaaccetgaaggagaagttcgagggtctgtgcaaggtc 1726

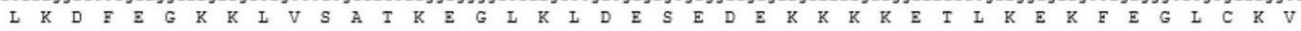
gtcaaggatattctgggcgacaaagtggagaaggtcgtggtctccgaccgagtcgtggactcccegtgttgcttggttaccggcgagtatgggtggaccgecaacatggagaggatcatgaaggca 1852

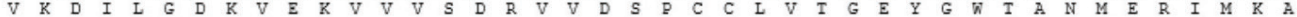
caggccttgagggactccagcatggcggggtacatgtcaagcaagaagaccatggagatcaacccggagaaccccataatggaggagctcaggaagcgggcagatgcagacaagaatgacaagtcg 1978

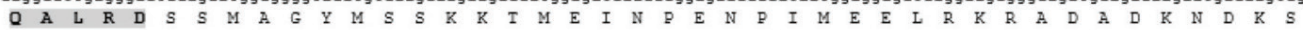
gtgaaggaccttgtgetgetcctattcgagactgecetcetcacatccggtttcagectcgacgaccccaacaccttcggcaacagaattcaccggatgetgaagetgggtctcagcattgacgag 2104

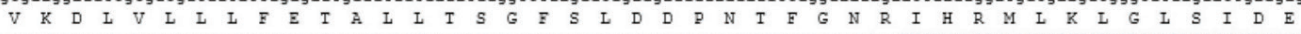
gaagatgcgecggcagacgcagatgcegacatgccttcgetcgaggacgetgatggegagggaagcaagatggaggaggtggactaaATCATCTCTTCTCCTCGGAAGGAGCATTCGCTCTATCTC 2230

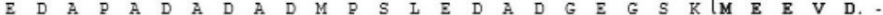
GGAGTTTGCCATGCGGAGGGTTACCCCTTATATTCTCTCTACTAATTAAAACGTAGTCTGAACTCTTAAGATGAGACTTTGCAGTCTCGTATCATGCTTACGCCGAGTGTCATCTGTTTTGCTGCC 2356

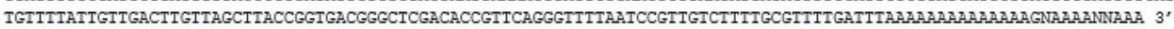

Figure 2: The full-length sequence of CcHsp90-2 corresponding genes with translated 700 amino acid of open reading frame, possesses eleven conserved amino acids signature sequence motif characteristics of the Hsp90 family and a C-terminus MEEVD penta-peptide characteristic of the cytosolic Hsp90 isoform 


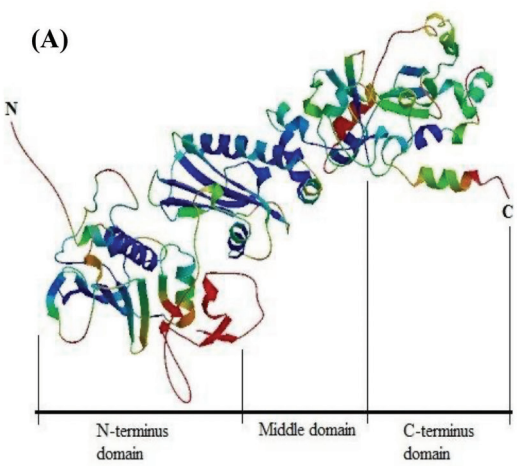

(B)

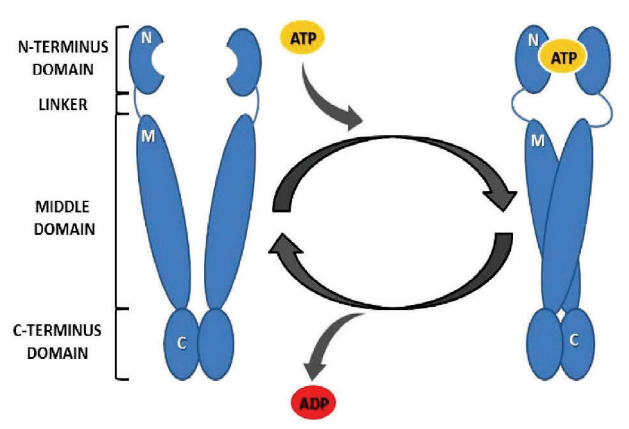

Figure 3: The CcHsp90-2 protein structure. (A) The predicted molecular model for $\mathrm{CcHsp} 90-2$ protein with expected molecular weight of $79.95 \mathrm{kDa}$. (B) Pincer movement of CcHsp90-2 coupled to the ATPase cycle

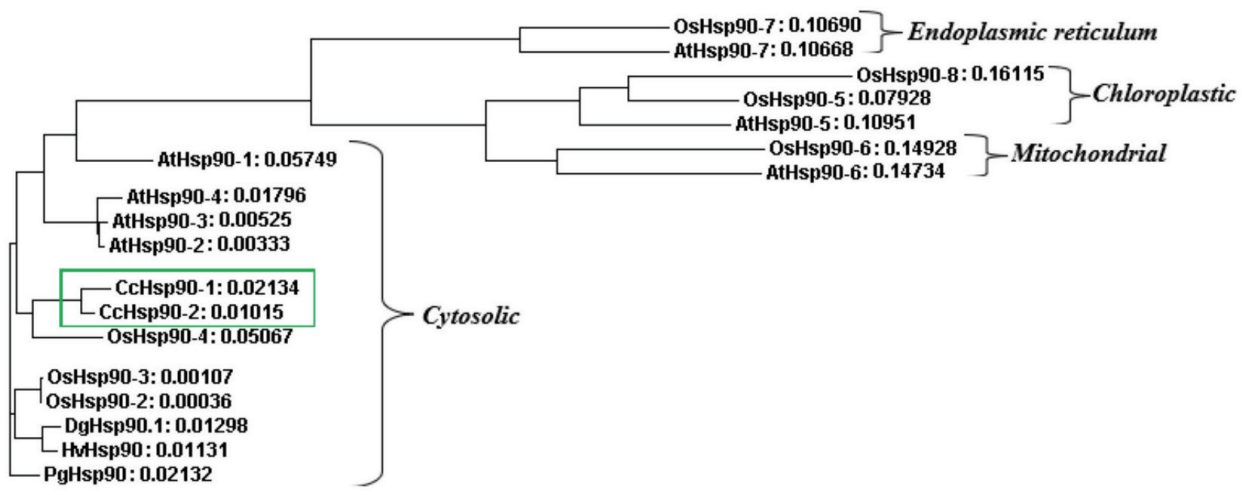

Figure 4: The relative distance of the CcHsp90 proteins to various plants HSP90 family (seven HSP90s of Arabidopsis, seven HSP90s of the rice genome, two of Dactylis glomerata cytosolic HSP90, Hordeum vulgare cytosolic HSP90 and Pennisetum glaucum cytosolic HSP90), which are divided into four major monophyletic clades namely; endoplasmic reticulum, cytosolic, chloroplastic and mitochondrial by ClustalW2 program. The phylogenetic analysis showed that $\mathrm{CcHsp} 90$ proteins shared significant sequence identity to cytosol specific HSP90 homologs. The numbers behind are the proportional distance between the sequences

\section{Expression Levels of CcHsp90 Genes under Salinity Treatment}

The banding pattern of amplified product shows that the designed primers generated an expected fragment size, which was then successfully cloned and sequenced. Both target genes ( $\mathrm{CcHsp}$ 90-1 and CcHsp90-2) produced 144 bp, while Cc18S rRNA gene (reference gene) amplified a $187 \mathrm{bp}$ fragment (Figure 5). The relative expressions of CcHsp $90-1$ and CcHsp90-2 genes after normalization with the Cc18S rRNA gene toward salinity stress are shown in Figure 6 and the control was untreated plantlets or plantlets without seawater. Interestingly, the expression of the CcHsp90-2 gene was at an optimum level, at 8.94-fold compared to control. However, the CcHsp90-1 gene reached its optimum expression level at eight hours post-treatment (5.66-fold). This is earlier than the expression level recorded in rice (Liu et al., 2006) and pearl millet salt-tolerant plant (Reddy et al., 2011), which was 24 hours post-treatment for both. Moreover, the optimum expression fold of CcHsp90 genes was also higher than pearl millet HSP90 (only 2.75-fold expression). Nevertheless, the CcHsp 90 genes 
expression remained for only 16 hours of posttreatment compared to rice, which lasted for 72 hours (Liu et al., 2006). Early gene expression that lasted briefly after a period of time might be due to salinity level. Seawater used in the present study contained $500 \mathrm{mM} \mathrm{NaCl}$, which was 3and 6-times higher than $\mathrm{NaCl}$ concentration used in pearl millet, 150mM (Reddy et al., 2011) and rice, $80 \mathrm{mM}$ (Liu et al., 2006), respectively.

In vitro protein synthesis depends on physiological potassium in the range of 100-150 $\mathrm{mM}$. The presence of sodium at concentrations above $100 \mathrm{mM}$ will cause competition of $\mathrm{Na}^{+}$ for potassium binding sites thus resulting in alteration of $\mathrm{K}^{+} / \mathrm{Na}^{+}$ratios and $\mathrm{Na}^{+}$and $\mathrm{Cl}^{-}$ ion concentrations that is inimical to plants (Blumwald et al., 2000), which leads to misfolding and degradation of protein (Serrano et al., 1999). Moreover, salinity stress not only causes the nascent polypeptide to face errorprone folding, but it also involves a large portion. Misfolded proteins are dangerous to cells, since they may be prone to spurious interactions or be endowed with undesirable biological activities (Ceriotti, 2011). Additionally, demand for "protein folders" might be another reason for early up-regulation of CcHsp 90 gene transcription under salinity stress in $C$. ciliata leaf. Protein folders help other proteins fold properly into the functional conformation and neutralizes the stress-induced protein damage (Tichá et al., 2020). Quantification of the expression of cytosolic CcHsp90-1 and CcHsp90-2 genes toward salinity stress (at mRNA transcript level) would provide a better picture to understand the mechanism.

Based on relative expression pattern and CcHsp90-2/CcHsp90 gene expression ratio, the results strongly support work by Prasinos et al. (2005) that cytosolic HSP90 members are prominent and play distinctive roles towards stresses. CcHsp90-2 gene optimum level time was four hours earlier than CcHsp90-1 gene, where the expression ratio for both genes show clear difference at four hours post-treatment ( $\mathrm{CcHsp} 90-2$ expression 2.38X higher than $\mathrm{CcHsp90-1)}$ and eight-hour treatment ( $\mathrm{CcHsp}$ 90-2 expression 1.5X higher than CcHsp90-1). This suggests that both genes play an important role in salinity stress, but they respond to their own specific targets and substrates, controlled by their specific promoter element factors (Floris et al., 2009; Zairul-Fazwan et al. 2015) resulting in different expression strength. Prasinos et al. (2005) showed that a cytosolic A. thaliana member's (AtHsp90-1 and AtHsp90-3) genes promoter revealed that the expression of corresponding genes was controlled by different regulatory elements and mechanisms. Nevertheless, the CcHsp 90 gene promoter and elements had been reported (Zairul-Fazwan et al., 2015).

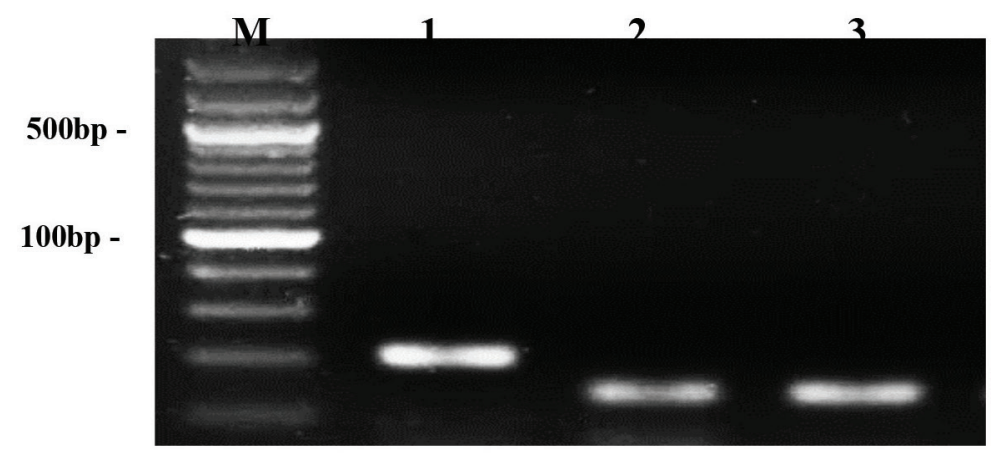

Figure 5: Gel electrophoresis of amplified Cc18S rRNA (housekeeping gene) and CcHsp90-1 and CcHsp90-2 gene using qPCR primer. Note M: 100 bp plus DNA ladder (Vivantis, Malaysia). Lane 1: partial of Cc18S rRNA gene (187 bp amplicon). Lane 2: partial of CcHsp90-1 gene (146 bp amplicon). Lane 3: partial of $C c H s p 90-2$ gene (144 bp amplicon) 


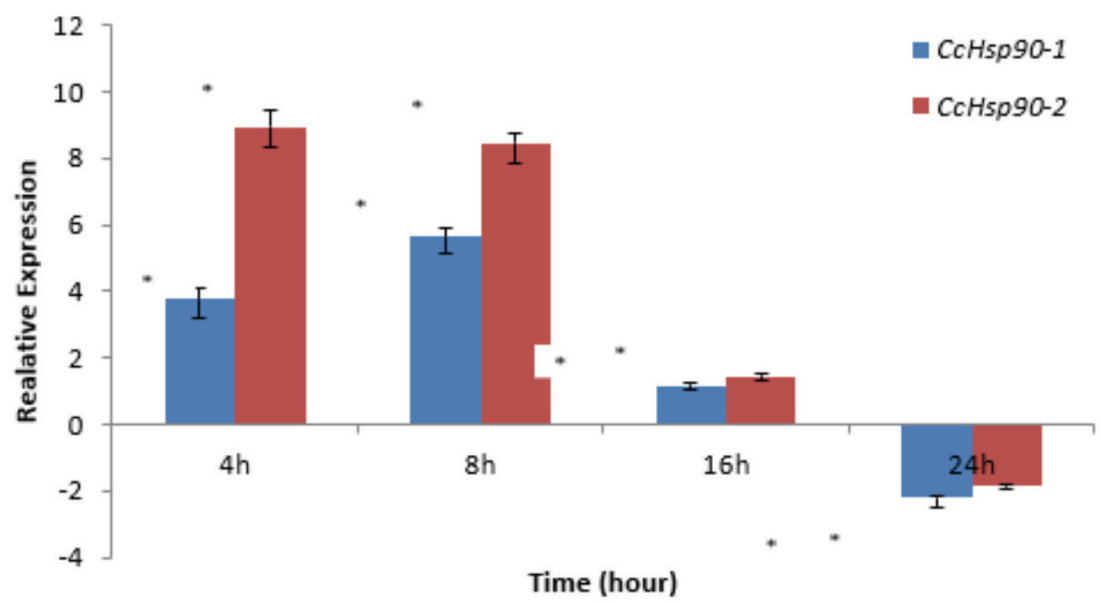

Figure 6: Expression of $C c H s p 90-1$ and $C c H s p 90-2$ genes towards salinity stress. The relative expression fold of different exposure time towards seawater $(29.0 \mathrm{ppt})$. The expression level was represented as mean fold change $\pm \mathrm{SD}$. The relative expression fold was generated by the calculated $2^{-\Delta \Delta \mathrm{Ct}}$ values $\left({ }^{*} p<0.05\right)$

\section{Conclusion}

The full-length cytosolic HSP90 protein gene of $C$. ciliata (CcHsp90-2) was successfully isolated. The gene encodes 700 amino acids with a predicted molecular mass of $79.95 \mathrm{kDa}$ and consists of three domains: N-terminus ATPbinding domain (1 to $211 \mathrm{~N})$, middle-client protein-interacting domain (281 to $540 \mathrm{~N}$ ), C-terminus dimerization domain (541 to $700 \mathrm{~N}$ ). The N-terminus and middle domain are linked by a charged-linker domain (212 to $280 \mathrm{~N}$ ). The CcHsp90-2 amino acid sequence possesses eleven conserved amino acid signature sequence motifs characteristic of the HSP90A subfamily. The CcHsp90-2 protein is evolutionarily closely related to other plant cytosolic HSP90 proteins, with a high sequence homology ( 84 to $94 \%$ ) but share lower sequence homology with organelle and endoplasmic reticulum specific HSP90 isoforms. The relative expression of CcHsp90-1 and $C$ cHsp90-2 genes in C. ciliata were significantly up-regulated and connected to each other in response to salinity stress to meet the additional demand for protein folding support. Current findings provide baseline information to understand the role of cytosolic $\mathrm{CcHsp90}$ proteins toward salinity stress adaptation in plants. The CcHsp90 recombinant genes might be transformed to other plants for overexpression during environmental stresses.

\section{Acknowledgements}

This project was funded by the Ministry of Higher Education Malaysia under the Fundamental Research Grant Scheme (FRGS) Vote 59251.

\section{References}

Ahmad-Sofiman, O., Niels, J., \& Mashhor, M. (2009). Cryptocoryne of Peninsular Malaysia. Universiti Sains Malaysia. Penang.

Arnold, K., Bordoli, L., Kopp, J., \& Schwede, T. (2006). The SWISS-MODEL Workspace: A web-based environment for protein structure homology modelling. Bioinformatics, 22, 195-201.

Aziza, S., Fatiha, E. K., \& Abdelaziz, S. (2002). Analysis of dystrophin gene deletions by multiplex PCR in Moroccan patients. Journal of Biomedicine and Biotechnology, 2(3), 158-160.

Barsanjit, M., Vasudevan, S., \& Paul, L. F. (2003). Translational control by the 30 - 
UTR: The ends specify the means. Trends in Biochemical Sciences, 28(2), 91-98.

Blumwald, E., Aharon, G. S., \& Apse, M. P. (2000). Review: Sodium transport in plant cells. Biochimica Et Biophysica Acta, 1465, 140-151.

Bot, A. J., Nachtergaele, F. O., \& Yong, A. (2000). Land resource potential and constrains at regional and country levels. FAO World Soil Resources Reports, 05320488, No. 90.

Borrone, J. W., Kuhn, D. N., \& Schnell, R. J. (2004). Isolation, characterization, and development of WRKY genes as useful genetic markers in Theobroma cacao. Theoretical and Applied Genetics, 109, 495-507

Buchner, J. (1999). Hsp90 \& Co- a holding for folding. Trends in Biochemical Sciences, 24, 136-141.

Ceriotti, A. (2011). Waste disposal in the endoplasmic reticulum, ROS production, and plant salt stress response. Cell Research, 21, 555-557.

Chatterjee, S., \& Pal, J. K. (2009). Role of 5'and 3'-untranslated regions of mRNAs in human diseases. Biology of the Cell, 101, 251-262.

Chen, B., Zhong D., \& Monteiro, A. (2006). Comparative genomics and evolution of the Hsp90 family of genes across all kingdoms of organisms. BMC Genomics, 7, 156.

Condon, A. (2003). Problems on RNA secondary structure prediction and design. Lecture Notes in Computer Science, 2719, 22-32.

Duwat, P., Ehrlich, S. D., \& Gruss, A. (1992). Use of degenerate primers for polymerase chain reaction cloning and sequencing of the Lactococcus lactis subsp. lactis recA gene. Applied and Environmental Microbiology, 58(8), 2674-2678.

Elnifro, E. M., Ashshi, A. M., Cooper, R. J., \& Klapper P. E. (2000). Multiplex PCR: Optimization and application in diagnostic virology. Clinical Microbiology Reviews, 4(3), 559-570.

Felts, S. J., \& Toft, D. O. (2003). P23, a simple protein with complex activities. Cell Stress Chaperones, 8, 108-113.

Floris, M., Mahgoub, H., Lanet, E., Robaglia, C., \& Menand, B. (2009). Post-transcriptional regulation of gene expression in plants during abiotic stress. International Journal of Molecular Sciences, 10, 3168-3185.

Freeman, B. C., Myers, M. P., Schumacher, R., \& Morimoto, R. I. (1995). Identification of a regulatory motif in Hsp70 that affect ATPase activity, substrate binding, and interaction with HDJ-1. European Molecular Biology Organization, 14, 2281-2292.

Froger,A., \& Hall, J.E. (2007). Transformation of plasmid dna into $e$. coli using the heat shock method. Journal of Visualized Experiments, 6. http://www.jove.com/index/Details. stp?ID=253, doi: $10.3791 / 253$.

Gamborg, O. L. (1967). Aromatic metabolism in plants. V. the biosynthesis of chlorogenic acid and lignin in potato cell cultures. Canadian Journal of Biochemistry, 45, 1451-1457.

Grenert, J. P., Sullivan, W. P., Fadden, P., Haysted, T. A., Clark, J., Mimnaugh, E., Krutzch, H., Ochel, H. J., Schulte T. W., Suasville E., Neckers, L. M., \& Toft, D. O. (1997). The amino-terminal domain of heat shock protein 90 (hsp90) that binds geldamycin in an ATP/ADP switch domain that regulates hsp90 conformation. The Journal of Biological Chemistry, 272(38), 23843-23850.

Hainzl, O., Lapina, M.C., Buchner, J., \& Richter, K. (2009). The charged linker region is an important regulator of Hsp90 function. The Journal of Biological Chemistry, 284(34), 22559-22567.

Hayden, M. J., Nguyen, T. M., Waterman, A., \& Chalmers, K. J. (2008). Multiplex-ready PCR: A new method for multiplexed SSR 
and SNP genotyping. BMC Genomics, 9, 80 .

Heffer, A., \& Pick, L. (2011). Rapid isolation of gene homologs across taxa: Efficient identification and isolation of gene orthologs from non-model organism genomes, a technical report. EvoDevo, 2, 7.

Invitrogen. (2004). 5' RACE System for rapid amplification of cDNA Ends, Version 2.0. Invitrogen ${ }^{T M}$ Life Technologies. Www. invitrogen.com.

Isayenkov, S. V., \& Maathuis F. (2019). Plant salinity stress: Many unanswered questions remain. Frontiers in Plant Science, 10, 80.

Ito-Harashima, S., Kuroha, K., Tatematsu, T., \& Inada, T. (2007). Translation of the poly(A) tail plays crucial roles in nonstop mRNA by proteasome in yeast surveillance via translation repression and protein destabilization. Genes and Development, 21, 519-524.

Kiefer, F., Arnold, K., Künzli, M., Bordoli, L., \& Schwede, T. (2009). The SWISS-MODEL Repository and associated resources. Nucleic Acids Research, 37, D387-D392.

Kim, R. H., Kim, R., Chen, W., Hu, S., Shin, K. H., Park, N. H., \& Kang, M. K. (2008). Association of hsp90 to the hTERT promoter is necessary for hTERT expression in human oral cancer cells. Carcinogenesis, 29(12), 2425-2431.

Kosmaoglou, M., Schwarz, N., Bett, J. S., \& Cheetham, M. E. (2008). Molecular chaperones and photoreceptor function. Progress in Retinal and Eye Research, 27, 434-449.

Kumar, V., Shriram, V., Kishor, P. B. K., Jawali, N., \& Shitole, M. G. (2010). Enhanced proline accumulation and salt stress tolerance of transgenic indica rice by over-expressing P5CSF129A gene. Plant Biotechnology Report, 4, 37-48.

Krishna, P., \& Gloor, G. (2001). The Hsp90 family of proteins in Arabidopsis thaliana. Cell Stress Chaperones, 6, 238-246.
Legay, S., Lamoureux, D., Hausman, J. F., Hoffmann, L., \& Evers, D. (2009). Monitoring gene expression of potato under salinity using cDNA microarrays. Plant Cell Reports, 28, 1799-1816.

Li, W., Chen, Y., Ye, M., Wang D., \& Chen Q. (2020). Evolutionary history of the heat shock protein 90 (Hsp90) family of 43 plants and characterization of Hsp90s in Solanum tuberosum. Molecular Biology Reports. https://doi.org/10.1007/s11033020-05722-x

Liu, D., Zhanga, X., Chenga, Y., Takanob, T., \& Liua, S. (2006). rHsp90 gene expression in response to several environmental stresses in rice (Oryza sativa L.). Plant Physiology and Biochemistry, 44, 380-386.

Livak, K., \& Schmittgen, T. (2001). Analysis of Relative Gene Expression Data Using Real-time Quantitative PCR and the $2^{-\Delta \Delta C}{ }_{T}$ Method. Methods, 25, 402-408.

Löffert, D., Seip, N., Karger, S., \& Kang, J. (1998). PCR optimization: Degenerate primers. Qiagen News, 2, 3-6.

Mahajan, S., \& Tuteja, N. (2005). Cold, salinity and drought stresses: An overview. Archives of Biochemistry and Biophysics, 444, 139158.

Matesic, L. E., Yip, R., Reuss, A. E., Swing, D. A., O'Sullivan, T. N., Fletcher, C. F., Copeland, N. G., \& Jenkins, N. A. (2001). Mutations in Mlph, encoding a member of the Rab effector family, cause the melanosome transport defects observed in leaden mice. Proceedings of the National Academy of Sciences, 98(18), 10238-10243.

Mohanty, A., Kathuria, H., Ferjani, A., Sakamoto, A., Mohanty, P., Murata, N., \& Tyagi A. K. (2002). Transgenics of an elite indica rice variety Pusa Basmati 1 harbouring the codA gene are highly tolerant to salt stress. Theoretical and Applied Genetics, 106, 5157.

Munns, R., Cramer, G. R., \& Ball, M. C. (1999). Interactions between rising CO2, 
soil salinity and plant growth. In Luo, Y., Mooney, H. A., (Eds.), Carbon dioxide and environmental stress (pp. 139-167). London: Academic Press.

Munns, R. (2002). Comparative physiology of salt and water stress. Plant, Cell and Environment, 25(2), 239-250.

Nakayama, H., Horie, T., Yonamine, I., Shinmyo, A., \& Yoshida, K. (2005). Improving salt tolerance in plant cells. Plant Biotechnology, 22, 477-487.

Neilson, J. R., \& Sandberg, R. (2010). Heterogeneity in mammalian RNA 3' end formation. Experimental Cell Research, 316(8), 1357-64.

O'mullane, L., \& Eperon, I. C. (1998). The premRNA 59 cap determines whether U6 small nuclear RNA succeeds U1 small nuclear Ribonucleoprotein particle at 59 splice sites. Molecular and Cellular Biology, 18(12), 7510-7520.

Prodromou, C., Piper, P. W., \& Pearl, L. H. (1996). Expression and crystallisation of the yeast Hsp 82 chaperone and preliminary $\mathrm{X}$-ray diffraction studies of the aminoterminal domain. Proteins: Structure, Function, and Genetics, 25, 517-522.

Pfaffl, M., Horgan, G., \& Dempfle, L. (2002). Relative expression software tool $\left(\mathrm{REST}^{\circ}\right)$ for group-wise comparison and statistical analysis of relative expression results in real-time PCR. Nucleic Acids Research, 30(9), e36.

Prasad, M., Varshney, R. K., Roy, J. K., \& Balyan, H. S. (2000). The use of microsatellites for detecting DNA polymorphisms, genotype identification and genetic diversity in wheat. Theoretical and Applied Genetics, 100(3), 584-592.

Prasinos, C., Krampis, K., Samakovli, D., \& Hatzopoulos, P. (2005). Tight regulation of expression of two Arabidopsis cytosolic Hsp90 genes during embryo development. Journal of Experimental Botany, 412(56), 633-644.
Reddy, P. S., Thirulogachandar, V., Vaishnavi, C. S., Aakrati, A., Sopory, S. K., \& Reddy M. K. (2011). Molecular characterization and expression of a gene encoding cytosolic Hsp90 from Pennisetum glaucum and its role in abiotic stress adaptation. Gene, 474, 29-38.

Richter, J. D. (1999). Cytoplasmic polyadenylation in development and beyond. Microbiology and Molecular Biology Reviews, 63(2), 446-56.

Richter, K., \& Buchner, J. (2001). Hsp90: Chaperoning signal transduction. Journal of Cellular Physiology, 188, 281-290.

Roy, S. J., Negrão, S., \& Tester, M. (2014). Salt resistant crop plants. Current Opinion in. Biotechnology, 26, 115-124. doi: 10.1016/j. copbio.2013.12.004

Rutherford, S. L., \& Lindquis, S. (1998). Hsp90 as a capacitor for morphological evolution. Nature, 396, 336-342.

Ryan, K., \& Bauer, D.L. (2008). Finishing touches: Post-translational modification of protein factors involved in mammalian premRNA 3' end formation. The International Journal of Biochemistry \& Cell Biology, 40(11), 2384-96.

Serrano, R., Mulet, J. M., Rios, G., Marquez, J. A., de Larrinoa, I. F., Leube, M. P., Mendizabal, I., Pascual-Ahuir, A., Proft, M., Ros, R., \& Montesinos, C. (1999). A glimpse of the mechanisms of ion homeostasis during salt stress. Journal of Experimental Botany, 50, 1023-1036.

Sherlock, J., Cirigliano, V., Petrou, M., Tutschek, B., \& Adinolfi, M. (1998). Assessment of diagnostic quantitative fluorescent multiplex polymerase chain reaction assays performed on single cells. Annals of Human Genetics, 62(1), 9-23.

Simon, A., Ipor, I. B., \& Tawan, C. S. (2008). Distribution patterns, growth and biomass allocation of Cryptocoryne ciliata (Roxburgh) Schott (Araceae) from Sungai Sarawak, Kuching, Sarawak, Malaysia. 
Tropical Life Sciences Research, 19(1), 4579.

Stebbins, C. E., Russo, A. A., Schneider, C., Rosen, N., Hartl, F. U., \& Pavletich, N. P. (1997). Crystal structure of an Hsp90geldanamycin complex: Targeting of a protein chaperone by an antitumor agent. Cell, 89, 239-250.

Taipale, M., Jarosz D. F., \& Lindquist S. (2010). Hsp90 at the hub of protein homeostasis: Emerging mechanistic insights. Nature Reviews Molecular Cell Biology, 11, 515528 doi: 10.1038/nrm2918.

Takahashi, A., Casais, C., Ichimura, K., \& Shirasu, K. (2003). Hsp90 interacts with RAR1 and SGT1 and is essential for RPS2mediated disease resistance in Arabidopsis. Proceedings of the National Academy of Sciences, 100(20), 11777-11782.

Tichá, T., Samakovli, D., Kuchařová, A., Vavrdová, T., \& Šamaj, J. (2020). Multifaceted roles of heat shock protein 90 molecular chaperones in plant development. Journal of Experimental Botany, 71(14), 3966-3985.

Wandinger, S. K., Richter, K., \& Buchner, J. (2008). The Hsp90 chaperone machinery. Journal of Biological Chemistry, 283, 18473-18477.

Wang, W., Vinocur, B., Shoseyov, O., \& Altman, A. (2004). Role of plant heat-shock proteins and molecular chaperones in the abiotic stress response. Trends in Plant Science, 9(5), 244-252.
Wegele, H., Muller, L., \& Buchner, J. (2004). Hsp70 and Hsp90- a relay team for protein folding. Reviews of Physiology, Biochemistry and Pharmacology, 151, $1-44$.

Wei, Y., Liu, W., Hu, W., Yan, Y., \& Shi, H. (2020). The chaperone MeHSP90 recruits MeWRKY20 and MeCatalase1 to regulate drought stress resistance in cassava. New Phytology, 226(2), 476-491. https://doi. org/10.1111/nph.16346

Young, J. C., \& Hartl, F. U. (2000). Polypeptide release by Hsp90 involves ATP hydrolysis and is enhanced by the co-chaperone $\mathrm{p} 23$. EMBO Journal, 19, 5930-5940.

Young, J. C., Obermann, W. M. J., \& Hartl, F. U. (1998). Specific binding of tetratricopeptide repeat proteins to the $\mathrm{C}$-terminal $12-\mathrm{kDa}$ domain of hsp90. The Journal of Biological Chemistry, 273(29), 18007-18010.

Zairul-Fazwan, M. Z., Aziz, A., \& Cha, T. S. (2015). Isolation and characterization of heat-shock protein 90 (HSP90) specific promoter of Cryptocoryne ciliata. Malaysian Applied Biology, 44(1), 83-87.

Zou, S., Stansfield, C., \& Bridge, J. (1998). Identification of new influenza B virus variants by multiplex reverse transcriptionPCR and the heteroduplex mobility assay. Journal of Clinical Microbiology, 36(6), 1544-1548. 